\title{
Fall in peak expiratory flow during haemodialysis in patients with chronic renal failure
}

\author{
A DAVENPORT, A J WILLIAMS
}

From the Renal Unit, Royal Liverpool Hospital, and Adult Cardiothoracic Unit, Broadgreen Hospital, Liverpool

ABSTRACT Peak expiratory flow rate (PEF) was measured during haemodialysis in 30 unselected patients with chronic renal failure. The patients attended the hospital dialysis unit, where they received regular dialysis using a cuprophan dialyser with acetate buffered dialysate. Mean PEF had fallen by $60 \mathrm{l} / \mathrm{min}(13 \%) 30$ minutes after the start of dialysis. In 10 of the 30 patients the fall in PEF was over $15 \%$, the maximum fall being $32 \%$. After the initial fall PEF increased throughout the next 2.5 hours of haemodialysis, but it fell again at five hours in the 14 patients who had been dialysed for four hours. During dialysis there was a reduction in blood white cell and platelet counts and in arterial oxygen tension at 30 and 60 minutes $(p<0.05)$ and the white cell count and arterial oxygen tension were still reduced at three hours. The coincidence of the fall in PEF at 30 minutes and the fall in arterial oxygen tension suggests that bronchoconstriction might contribute to dialysis induced hypoxaemia by causing ventilation-perfusion disturbances. Appreciable airway dysfunction occurred in all the patients undergoing regular haemodialysis with new cuprophan dialysers and acetate buffered dialysate.

\section{Introduction}

This study was undertaken after one patient, with a history of wheeze, developed bronchoconstriction repeatedly during dialysis with a new cuprophan (reconstituted cellulose) dialyser. She required treatment with nebulised salbutamol, intravenous hydrocortisone, and oxygen on each occasion. This dialysis induced asthma resolved when the cuprophan dialyser was changed to one made of polycarbonate.

There have been single case reports of patients who developed bronchoconstriction during' haemodialysis,,$^{12}$ in some cases only when dialysis was carried out with cuprophan dialysers. ${ }^{2}$ Airway function during haemodialysis has received little attention otherwise. Previous studies of respiratory function have concentrated on defects in gas exchange at the alveolar-capillary membrane ${ }^{3}$ or on changes in minute ventilation ${ }^{4}$ or tidal volume ${ }^{5}$ in an attempt to explain the hypoxaemia that develops during dialysis with a cuprophan dialyser and against a dialysate buffered with acetate. ${ }^{6}$

We decided therefore to measure peak flow rates Address for reprint requests: Dr A Davenport, Renal Unit, St James's
University Hospital, Leeds LS9 7TF.

Accepted 17 June 1988 throughout the procedure in patients undergoing regular dialysis and to relate changes in PEF to dialysis associated hypoxaemia.

\section{Method}

All 30 patients who attended the hospital haemodialysis ward regularly for dialysis with the Gambro AK 10 artificial kidney machine were enrolled in the study. The machines had a new $1 \mathrm{~m}^{2}$ flat plate cuprophan dialyser (Gambro AB, Lundia, Sweden) and used dialysate buffered with acetate.

The 30 patients included 24 men and their mean age was 46 (range 18-66) years. They had been receiving dialysis treatment for 6-148 months. The mean duration of a dialysis session was $4 \cdot 3$ (range 3-6) hours, mean blood flow through the dialyser was 267 (range 200-300) $\mathrm{ml} / \mathrm{min}$, and mean transmembrane pressure was 77 (range 0-200) $\mathrm{mm} \mathrm{Hg}$. Mean weight loss during dialysis was 1.4 (range $0 \cdot 8-1 \cdot 8) \mathrm{kg}$. Patients answered a detailed questionnaire about any past history of allergic phenomena, smoking habits, respiratory symptoms, and symptoms during dialysis.

Each patient was instructed in the use of a Wright mini peak flow meter. Peak flow measurements were recorded immediately before the patient was connected to the extracorporeal circuit, at 30,60 and 180 
minutes after the start of dialysis, and then at hourly intervals until dialysis was completed. At each time the mean of three PEF values was recorded, provided that there was a difference of less than $201 / \mathrm{min}$ between the three measurements. Predicted PEF values were calculated for each patient according to their age, sex, and height. ${ }^{\text {? }}$

Blood samples were withdrawn before dialysis for measurement of peripheral eosinophil count, serum IgE concentrations, and ethylene oxide antibodies. In 15 patients arterial blood samples were taken immediately before dialysis and at 30,60 and 180 minutes during dialysis for measurement of arterial blood gas tensions and peripheral blood counts.

Patients were excluded from the analysis if at the start of dialysis they were $\mathbf{2} \mathbf{~ k g}$ or more from their ideal dry weight, to minimise the effect of salt and water retention and possibly pulmonary oedema on PEF. Patients were also excluded if they had renal failure associated with systemic disease known to be associated with asthma-for example, polyarteritis nodosa.

Statistical analysis was by Student's paired $t$ test and by analysis of variance. The Spearman rank correlation test was used to test for correlations.

\section{Results}

Five of the 30 patients were current cigarette smokers and five were ex-smokers. One smoker and one nonsmoker complained of a regular cough but this was not consistent enough to fulfil the Medical Research Council criteria for chronic bronchitis. No patient had a history of asthma or any other atopic disease. Family histories, when available, were also negative for allergic disease. No patient was receiving corticosteroid or bronchodilator treatment. During the study no patient complained of shortness of breath during dialysis.

All 30 patients had normal peripheral blood eosinophil counts $\left(<0.4 \times 10^{9} / 1\right)$ and normal total serum IgE concentrations $(<100 \mathrm{IU} / \mathrm{ml})$. No patient had serum IgE antibodies to ethylene oxide-albumin detected by radioallergosorbent testing.
Table 1 Peak expiratory flow (PEF) values before and 30 जे minutes after the start of dialysis

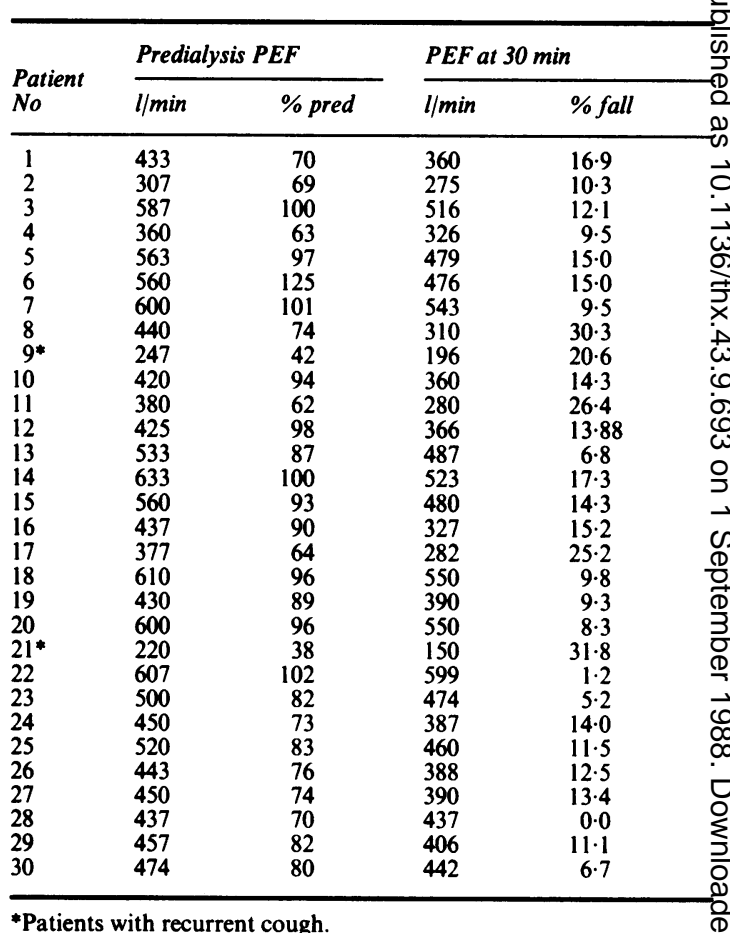

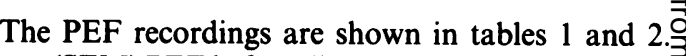
Mean (SEM) PEF before dialysis was significantly less than the predicted values $(469(19)$ v $573(11.5) \mathrm{l} / \mathrm{min}(\mathrm{p}$ $<0.001)$ ). During haemodialysis, mean PEF had fallen by $13 \%$, from 469 (19) to 407 (20) $1 / \mathrm{min}$, at 30 응 minutes $(p<0.01)$. Ten patients had a fall of $15 \%$ or more (individual data available on request), theo maximum fall being $32 \%$. There was a negative 3 . correlation between the predialysis PEF \% predicted and the fall in PEF at 30 minutes $(r=-0.52, p=3$ 0.004 ). There was no correlation between the amounto of fluid removed during dialysis and either the predialysis PEF \% predicted $(r=-0.07, p=0.72)$ oro the percentage fall in PEF at 30 minutes $(r=0 \cdot 19, p=$ $0 \cdot 31)$.

Table 2 Change in mean (SEM) peak expiratory flow (PEF) in all 30 patients during dialysis and arterial oxygen and carbon dioxide tensions $\left(\mathrm{PaO}_{2}, \mathrm{PaCO}_{2}\right)$, serum bicarbonate, and peripheral white cell (WBC) and platelet counts in 15 patients

\begin{tabular}{|c|c|c|c|c|c|c|}
\hline $\begin{array}{l}\text { Time } \\
(\min )\end{array}$ & $\begin{array}{l}P E F^{*} \\
(l / \min )\end{array}$ & $\begin{array}{l}\mathrm{PaO}_{2} \\
(\mathrm{kPa})\end{array}$ & $\begin{array}{l}\mathrm{PaCO}_{2} \\
(\mathrm{kPa})\end{array}$ & $\begin{array}{l}\text { Bicarbonate } \\
(\mathrm{mmol} / \mathrm{l})\end{array}$ & $\begin{array}{l}W B C \\
\left(10^{9} / 1\right)\end{array}$ & $\begin{array}{l}\text { Platelets } \\
\left(10^{12} / 1\right)\end{array}$ \\
\hline $\begin{array}{c}\text { Before } \\
30 \\
60 \\
180\end{array}$ & $\begin{array}{l}469(19 \cdot 3) \\
407(20 \cdot 0) \dagger \\
428(21 \cdot 0) \\
428(21 \cdot 0)\end{array}$ & $\begin{array}{r}13.9(0.3) \\
10.1(1.2) \dagger \\
9.7(1.4) \dagger \\
11.3(1.5) \dagger\end{array}$ & $\begin{array}{l}4 \cdot 8(0 \cdot 7) \\
4 \cdot 7(1 \cdot 8) \\
4 \cdot 8(1 \cdot 1) \\
4 \cdot 7(1 \cdot 2)\end{array}$ & $\begin{array}{l}21.0(0.6) \\
21.2(1.1) \\
21.6(1.2) \\
23.9(1.6) \dagger\end{array}$ & $\begin{array}{l}6.9(0.5) \\
4.4(0.6) \dagger \\
6.1(0.6) \\
6.0(0.6)\end{array}$ & $\begin{array}{l}199(17) \\
165(10) \dagger \\
171(12) \dagger \\
187(12)\end{array}$ \\
\hline
\end{tabular}

*PEF at $240 \mathrm{~min}: 415(19) 1 / \min (n=29) ; 300 \mathrm{~min}: 410(31) 1 / \min (n=14) ; 360 \mathrm{~min}: 429(44) 1 / \min (n=11)$. tp $<0.05$ in the comparison with predialysis values. 

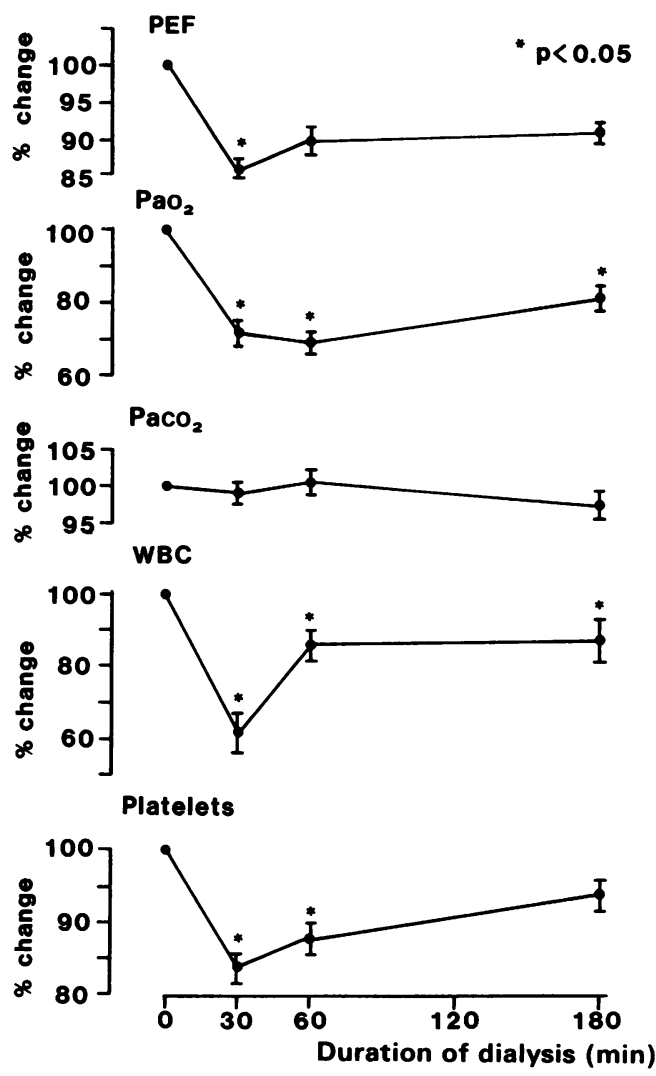

Mean (SEM) percentage change in peak expiratory flow (PEF) (baseline 469 (19.3) l/min); arterial oxygen tension $\left(\mathrm{PaO}_{2}\right.$ ) (baseline 13.9 (0.3) $\mathrm{kPa}$ ); arterial carbon dioxide tension $\left(\mathrm{PaCO}_{2}\right)$ (baseline $4.8(0 \cdot 7) \mathrm{kPa}$ ); peripheral white blood cell count $(W B C)$ (baseline 6.9 (0.5) $\left.\times 10^{9} / l\right)$, and platelet count (baseline $199(17) \times 10^{12} / \mathrm{l}$ ).

After 30 minutes PEF increased throughout the remainder of dialysis. In 14 patients who were dialysed for more than four hours, however, there was a second fall in PEF after five hours from 458 (26) to 410 (30) l/ $\min (\mathrm{p}=<0.05$ in the comparison with predialysis PEF values).

In the 15 patients whose arterial blood gas tensions were available there was a significant fall in oxygen tension $\left(\mathrm{PaO}_{2}\right)$ from predialysis values at all three times of analysis during dialysis, the maximum fall being at 60 minutes. There was a positive correlation between $\%$ fall in $\mathrm{PaO}_{2}$ and \% fall in PEF at 30 minutes $(\mathrm{r}=$ $0.65, \mathrm{p}<0.005$ ). Arterial carbon dioxide tensions $\left(\mathrm{PaCO}_{2}\right)$ did not change during dialysis; the calculated bicarbonate increased during dialysis but this increase was significant only at three hours.

Both the peripheral white blood cell and the platelet count fell during the early phase of dialysis. The time course of these changes was similar to that for PEF and $\mathrm{PaO}_{2}$ (figure). There was no significant correlation between fall in PEF during dialysis and fall in either peripheral white blood cell or platelet count.

\section{Discussion}

We have shown a significant fall in peak expiratory flow during the first half hour of dialysis treatment in patients undergoing regular hospital dialysis. The mechanism underlying the reduction in PEF is unknown but is probably related to the bioincompatibility of the dialyser membrane, causing the release of inflammatory mediators. ${ }^{8}$ This would result in the activation of complement, ${ }^{9}$ neutrophils, ${ }^{10}$ macrophages, 1 and platelets, ${ }^{12}$ with the potential for releasing mediators that could cause bronchoconstriction. $^{13}$

Various allergic reactions, including anaphylaxis, bronchoconstriction, flushing, and hypotension, have been reported in patients during dialysis. ${ }^{14}$ Most of these adverse reactions have occurred during dialysis with a new cuprophan dialyser, ${ }^{15}$ and have been reported to occur more frequently in patients with greater activation of complement during dialysis. ${ }^{16}$ Recently ethylene oxide, a sterilising agent used in the manufacture of both the dialyser and the blood lines, has been reported to cause allergic reactions during dialysis. ${ }^{17}$ In one study two thirds of the patients who had anaphylactic reactions had had wheezing during dialysis. ${ }^{18}$ In our study no patient had a raised total serum IgE concentration or a positive result in the radioallergosorbent test for ethylene oxide antibodies, suggesting that bronchoconstriction can occur in nonatopic patients and is unlikely to be related to ethylene oxide sensitivity.

The changes in peak flow rate during dialysis are likely to reflect a balance between the expected improvement due to the removal of fluid during dialysis and bronchoconstriction due to bioincompatibility. Respiratory function tests before and after dialysis in previous studies have shown an increase in both maximal mid expiratory flow rates and PEF, the increase being greater in patients who lost more than $2 \mathrm{~kg}$ during dialysis. ${ }^{19}$ This suggests that peribronchial oedema before dialysis could be one reason for the low PEF \% predicted in our population immediately before dialysis. Other causes, such as uraemic skeletal myopathy, ${ }^{20}$ could also be important.

The temporal relation between the fall in arterial oxygen tension 30 minutes after the start of dialysis and the fall in PEF suggests that the two might be linked, possibly as a result of inflammatory mediator release. The fall in $\mathrm{PaO}_{2}$ is unlikely to have been due entirely to the fall in PEF, but bronchoconstriction may have aggravated any hypoxaemia by increasing 
lung ventilation-perfusion inequalities. Other workers have reported an increase in complement activation associated with both a fall in $\mathrm{PaO}_{2}$ and an increase in lung closing volumes, suggesting airway narrowing. ${ }^{21}$

We would like to thank all the renal physicians at Sefton General Hospital for permitting us to study their patients and Mrs Marjorie Smith, secretary of the Yorkshire Kidney Research Fund, for secretarial help.

\section{References}

1 Hanai K, Horuchi T, Hanai J, et al. Haemodialysis associated asthma in a renal failure patient. Nephron 1979;25:247-8.

2 Aljama P, Brown P, Turner P, Ward MK, Kerr DNS. Haemodialysis triggered asthma. $\mathrm{Br} \mathrm{Med} J$ 1978;3: 251-2.

3 Graf H, Stummvoll HK, Haber P, Kovarik J. Pathophysiology of dialysis related hypoxaemia. Proc EDTA 1980;17:155-61.

4 Aurigemma NM, Feldman NT, Gottlieb M, Ingram RH, Lazarus JM, Lowrie EG. Arterial oxygenation during haemodialysis. $N$ Engl J Med 1977;297:871-3.

5 DeBacker WA, Verpooten GA, Borgonjon DJ, Vermiere PA, Lins RL, DeBroe ME. Hypoxaemia during haemodialysis: effects of different membranes and dialysate compositions. Kidney Int 1983;23:738-43.

6 Burns C, Scheinhorn D. Hypoxaemia during haemodialysis. Arch Intern Med 1982;142:1350-3.

7 Cotes JE. Lung function: assessment and application in medicine. 4th ed. Oxford: Blackwell, 1979.

8 Dumler $F$, Levin $N$. Leucopenia and hypoxaemia. Unrelated effects of haemodialysis. Arch Intern Med 1979;139:1103-6.

9 Craddock PR, Fehr J, Dalmaso AP, Bingham KL, Jacob HS. Haemodialysis leukopenia. Pulmonary vascular leukotasis resulting from complement activation by dialyzer cellaphane membranes. J Clin Invest
1977;59:879-88.

10 Kaplow LS, Goffinet JA. Profound neutropenia during the early phase of haemodialysis. JAMA 1968\% 203:1135-7.

11 Nguyen AT, Lethia C, Zingraff J, Herbelin A, Naret C. Descamps-Latscha B. Haemodialysis membran induced activation of phagocyte oxidative metabolisfff detected in vivo and in vitro with micro amounts o. whole blood. Kidney Int 1985;28:158-67.

12 Knudsen F, Nielson AH, Kristensen SD. The effect of dialyzer membrane material on intradialytic changes io platelet count, platelet aggregation, circulating platele aggregation and anti-thrombin III. Scand $J$ Urôt Nephrol 1985;19:227-32.

13 Morley J, Page CP, Sanjar S. Platelets in asthma. Lance 1985;ii:726-7.

14 Foley RJ, Reeves WB Acute anaphylactoid reactions haemodialysis. Am J Kidney Dis 1985;5:132-5.

15 Ing T, Daugirdas JT, Popli S, Gandhi VC. First use syndrome with cuprammonium cellulose dialyzers. Inn J Artif Organ 1983;6:235-9.

16 Hakim RM, Breillatt J, Lazarus JM, Port FK. Com plement activation and hyposensitivity reactions $t \overline{{ }^{2}}$ dialysis membranes. $N$ Engl J Med 1984;311:878-82.

17 Bommer J, Wilhelm OH, Bartha HP, Schindele H, Ritz Ece Anaphylactoid reactions in dialysis patients. Role o\$0 ethylene oxide. Lancet 1983;ii:1382-4.

18 Nicholls AJ, Platt MM. Anaphylactoid reactions during haemodialysis are due to ethylene oxide hypersen sitivity. Proc Eur Dial Transplant Assoc 1984;21:173-7응

19 Zidulka A, Despas PJ, Milic-Emili J, Anthonisen NR。 Pulmonary function with acute loss of excess lung water by haemodialysis in patients with chroni uraemia. Am J Med 1973;55:134-41.

20 Brautbar N. Skeletal myopathy in uraemia: abnorma energy metabolism. Kidney Int 1983;24:581-6.

21 Craddock PR, Fehr J, Brigham KL, Kronenberg RS Jacob HS. Complement and leukocyte mediated pul monary dysfunction in haemodialysis. $N$ Engl J Me $\overparen{\overparen{R}}$ 1977;296:769-74. 